\title{
CLINICAL NOTE
}

\section{Severe spruelike enteropathy due to olmesartan}

\author{
Gioia Fiorucci ${ }^{1}$, Efisio Puxeddu ${ }^{1}$, Renato Colella ${ }^{2}$, Gian Paolo Reboldi ${ }^{1}$, Vincenzo Villanacci ${ }^{3}$ \\ and Gabrio Bassotti ${ }^{4}$
}

Departments of ${ }^{1}$ Internal Medicine and ${ }^{2}$ Pathology. University of Perugia. Italy. ${ }^{3}$ Pathology Section. Spedali Civili and University of Brescia. Italy. ${ }^{4}$ Gastroenterology and Hepatology Section. Department of Clinical and Experimental Medicine. University of Perugia. Italy

\begin{abstract}
Villous atrophy and negative serologic testing is a diagnostic challenge, and the rarer possibility of drug-induced enteritis should be considered. We report a rare case of severe spruelike enteritis due to olmesartan that completely resolved after withdrawal of the drug. The possibility that patient labeled as "refractory" celiac disease may actually be due to drug treatment should always be taken into consideration, to avoid unnecessary investigations.
\end{abstract}

Key words: Celiac disease. Diarrhea. Enteropathy. Histology. Olmesartan.

\section{INTRODUCTION}

The presence of small bowel villous atrophy and negative serologic testing for celiac disease represents a difficult dilemma in clinical practice (1). The differential diagnoses include several intestinal disorders (e.g., bacterial overgrowth, ulcerative jejunitis, protein-losing enteropathy, T-cell lymphoma, and tropical sprue) (2), even though in recent years similar findings have been also reported following the use of drugs (3-6). To the latter it has been recently added olmesartan, sometimes responsible for an enteropathy and malabsorption mimicking celiac disease (7).

Fiorucci G, Puxeddu E, Colella R, Reboldi GP, Villanacci V, Bassotti $G$. Severe spruelike enteropathy due to olmesartan. Rev Esp Enferm Dig 2014;106:142-144.

Received: 03-10-2013

Accepted: $14-10-2013$

Correspondence: Gabrio Bassotti. Clinica di Gastroenterologia ed Epatologia. Ospedale Santa Maria della Misericordia. Piazzale Menghini, 1. 06156 San Sisto, Perugia. Italy

e-mail: gabassot@tin.it
We report a severe case of olmesartan-related enteropathy, to the best of our knowledge, the first from Italy that completely resolved after withdrawal of the drug.

\section{CASE REPORT}

A 68-year-old man was admitted to the Division of Internal Medicine in toward the end of December 2012 due to severe diarrhea, weight loss (about $10 \mathrm{~kg}$ ) and dehydration. The patient had been admitted a month before in another hospital for similar but lesser symptoms, and discharged after a few days with a diagnosis of viral gastroenteritis. Past medical history revealed hypertension treated with olmesartan, $40 \mathrm{mg}$ daily, in the last four years. On further questioning, the patient revealed that the onset of diarrhea was in March 2012, and it was treated with loperamide and potassium per os. However, due to the persistence of symptoms, his family physician required serology for celiac disease that yielded negative results, and a colonoscopy. The latter was reported as normal, and multiple biopsies were described as normal (H\&E stain).

On admission, the patient had negative physical findings, except cutaneous and mucosal dehydration and splenomegaly. Blood chemistry revealed hemoglobin $13 \mathrm{~g} /$ dL (n.v. 13-17), serum potassium $2.3 \mathrm{mEq} / \mathrm{L}$ (n.v. 3.5-55), calcium $6 \mathrm{mg} / \mathrm{dL}$ (n.v. 8.5-10.7), magnesium $0.8 \mathrm{mg} /$ $\mathrm{dL}$ (n.v. 1.5-2.6), phosphorus $2.4 \mathrm{mg} / \mathrm{dL}$ (n.v. 2.5-5), albumin $2.9 \mathrm{~g} / \mathrm{dL}$ (n.v. 3.5-5.5), prealbumin $15.5 \mathrm{mg} / \mathrm{dL}$ (n.v. 20-40), total protein $4.9 \mathrm{~g} / \mathrm{dL}$ (n.v. 6.2-8.5), B12 vitamin $103 \mathrm{pg} / \mathrm{mL}$ (n.v. 180-914), folic acid $2.7 \mathrm{ng} / \mathrm{mL}$ (n.v. 3-20). Abdominal ultrasound scans revealed mildly dilated small bowel loops in the epigastric area, mild hepatomegaly with steatosis, and biliary sludge. In the following days, the patient's conditions did not improve and, due to severe anorexia and further weight loss, total parenteral nutrition was started. Repeated stool examinations for infectious agents, including parasites and ova, were negative, as well 
as investigations aimed at individuating a possible neuroendocrine neoplasm. However, notwithstanding the use of oral loperamide and potassium i.v., diarrhea and hypokaliemia persisted. Therefore, upper panendoscopy was carried out, that revealed patchy erythema of antral mucosa and a mosaic pattern of the duodenal mucosa. Antral and duodenal histology (H\&E stain) showed respectively HP-negative chronic active inflammation and severe villous atrophy with severe inflammatory aspects. HLA typing showed the presence of DQ2 alleles but repeated serologic testing for celiac disease was negative. Due to worsening clinical conditions an abdominal CT scan with contrast medium was performed, that did not show pathological thickening of the small bowel, but showed the presence of multiple abdominal lymph nodes enlargement, especially in the mesenteric area. A gastroenterological evaluation hypothesized the association of the patient's clinical condition with the use of olmesartan (started about four years before the onset of diarrhea); a pathological re-evaluation (also of the colonic biopsies taken elsewhere before admission) by an expert gastrointestinal pathologist confirmed the previously described findings of severe villous atrophy. CD3 staining also revealed a pathologic increase of lymphocytes in the stomach (lymphocytic gastritis) and colon (lymphocytic colitis), a picture suggesting lymphocytic enteritis (Fig. 1). Thus, the drug was stopped, and the clinical picture almost disappeared within a week. The patient was discharged in mid-January 2013, with no symptoms and a complete normalization of the blood chemistry. A clinical follow-up after four months showed complete absence of intestinal symptoms, normal blood chemistry, and a weight gain of $14 \mathrm{~kg}$. The patient refused further endoscopic assessment and continues (August 2013) to enjoy good health.

\section{DISCUSSION}

To date, olmesartan-related enteropathy has been rarely reported in literature, mainly as single case reports $(8,9)$, or associate findings during evaluation of cohorts of celiac (1) or collagenous sprue patients (10), and only a relatively consistent case series (including 22 subjects) has been published (7). Albeit infrequent, this enteropathy may be quite severe in more than $50 \%$ of cases -to the point that it received a recent FDA warning (11)-, and it is often considered as unresponsive celiac disease (7).

To the best of our knowledge, the present case is the first reported from Italy; the symptoms were initially at-

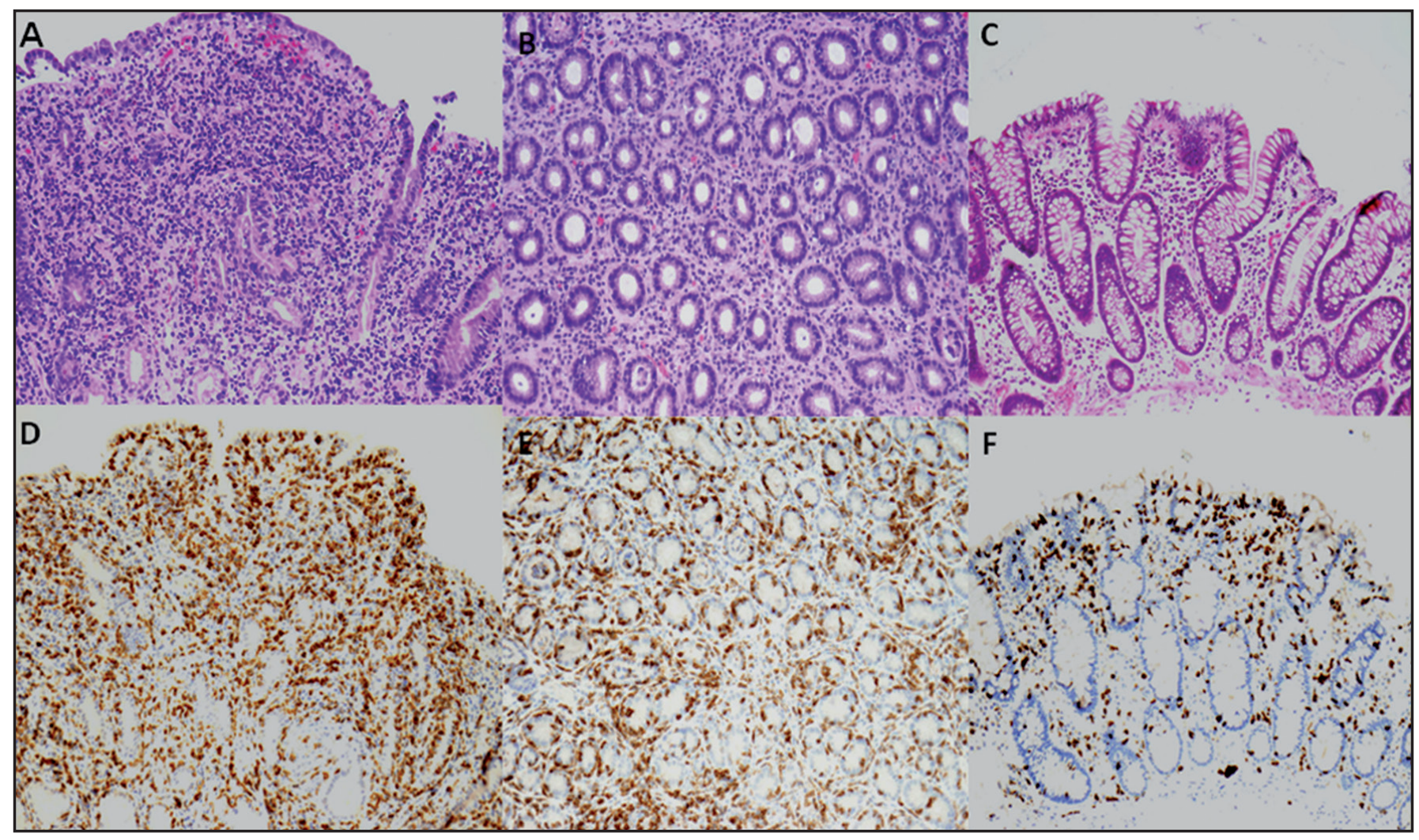

Fig. 1. A. Duodenal biopsy, showing villous atrophy (H\&E, original magnification x 20). B. Gastric antral biopsy, showing HP-negative active gastritis (H\&E, original magnification $\times 20$ ). C. Colonic biopsy, showing almost normal findings (H\&E, original magnification $\times 20)$. D-F. Duodenal, antral and colonic biopsies, showing pathological increase of T lymphocytes in superficial epithelium in duodenal and colonic biopsy and in the glands in the stomach (CD3 stain, original magnification $\times 20)$. 
tributed to an infectious, possibly viral, cause also due to the apparently normal colonoscopic and histological findings using conventional staining (H\&E). Interestingly, diarrhea appeared after four years of treatment; this is not unusual, since in the largest series the average onset of diarrhea was 3 years (7). In our patient, the availability of tissue from biopsy samples taken from the upper and lower gut allowed to establish the presence of so-called lymphocytic enteritis involving the stomach, the small bowel and the colon (Fig. 1). Due to the patient' unwillingness to repeat endoscopic procedures (since the clinical conditions improved dramatically soon after olmesartan withdrawal, and remained so during the follow-up) we could not document histological recovery; however, almost complete histological healing within two months of stopping the offending drug was documented in all patients in whom such follow-up was obtained (7), and paralleled the good clinical conditions. Thus, we may hypothesize that the same occurred in our case.

At present, the mechanisms responsible for the onset of enteritis after olmesartan use are unknown (7). Due to the demonstration that angiotensin receptor blockers inhibit the effects of transforming growth factor beta $(12,13)$, an important factor to maintain intestinal immune homeostasis $(14,15)$, it might be hypothesized that olmesartan interferes with such mechanisms leading to the development of enteritis. However, to date it is unknown whether other pharmaceutical compounds of similar class have such effects.

Thus, once again it is evident how the differential diagnosis of villous atrophy may be difficult, and that several possibilities must be taken into consideration when dealing with suspected "refractory" celiac disease $(1,7)$. Besides, physicians should be aware that normal colonoscopic findings in patients with unexplained diarrhea and negative serologic tests and stool cultures must not automatically led to a diagnosis of irritable bowel syndrome; indeed, there is mounting evidence that in such patients the presence of drug colitides must be carefully excluded by multiple ileal and colonic sampling and careful evaluation by expert gastrointestinal pathologists (16-18).

In conclusion, in the presence of "refractory" celiac disease the (albeit infrequent) possibility that a drug treatment might be responsible for the onset of symptoms and the enteric lesions should always be taken into consideration, since these entities easily and completely resolve soon after stopping the offending drug, to avoid frustrat- ing and unnecessary further, often invasive and expensive, procedures and give the patients a good quality of life.

\section{REFERENCES}

1. DeGaetani M, Tennyson CA, Lebwohl B, Lewis SK, Abu Daya H, Arguelles-Grande C, et al. Villous atrophy and negative celiac serology: A diagnostic and therapeutic dilemma. Am J Gastroenterol 2013;108:647-53.

2. Krauss N, Schuppan D. Monitoring nonresponsive patients who have celiac disease. Gastrointest Endosc Clin N Am 2006;16:317-27.

3. Kwo PY, Tremaine WJ. Nonsteroidal anti-inflammatory drug-induced enteropathy: Case discussion and review of the literature. Mayo Clin Proc 1995;70:55-61.

4. Ziegler TR, Fernández-Estívariz C, Gu LH, Fried MW, Leader LM. Severe villus atrophy and chronic malabsorption induced by azathioprine. Gastroenterology 2003;124:1950-7

5. Kamar N, Faure P, Dupuis E, Cointault O, Joseph-Hein K, Durand $\mathrm{D}$, et al. Villous atrophy induced by mycophenolate mofetil in renaltransplant patients. Transpl Int 2004;17:463-7.

6. Weclawiak H, Ould-Mohamed A, Bournet B, Guilbeau-Frugier C, Fortenfant F, Muscari F, et al. Duodenal villous atrophy: A cause of chronic diarrhea after solid-organ transplantation. Am J Transplant 2011;11:575-82.

7. Rubio-Tapia A, Herman ML, Ludvigsson JF, Kelly DG, Mangan TF, Wu TT, et al. Severe spruelike enteropathy associated with olmesartan. Mayo Clin Proc 2012;87:732-8.

8. Dreifuss SE, Tomizawa Y, Farber NJ, Davison JM, Sohnen AE. Spruelike enteropathy associated with olmesartan: An unusual case of severe diarrhea. Case Rep Gastrointest Med 2013;2013:618071.

9. Stanich PP, Yearsley M, Meyer MM. Olmesartan-associated sprue-like enteropathy. J Clin Gastroenterol 2013 (in press).

10. Rubio-Tapia A, Talley NJ, Gurudu SR, Wu TT, Murray JA. Glutenfree diet and steroid treatment are effective therapy for most patients with collagenous sprue. Clin Gastroenterol Hepatol 2010;8:344-9.e3.

11. FDA Drug Safety Communication: FDA approves label changes to include intestinal problems (sprue-like enteropathy) linked to blood pressure medicine olmesartan medoxomil. Available at: http://www. fda.gov/Drugs/DrugSafety/ucm359477.htm

12. Kagami S, Border WA, Miller DE, Noble NA. Angiotensin II stimulates extracellular matrix protein synthesis through induction of transforming growth factor-beta expression in rat glomerular mesangial cells. J Clin Invest 1994;93:2431-7.

13. Matt P, Schoenhoff F, Habashi J, Holm T, Van Erp C, Loch D, et al. Circulating transforming growth factor-beta in Marfan syndrome. Circulation 2009;120:526-32.

14. Coombes JL, Robinson NJ, Maloy KJ, Uhlig HH, Powrie F. Regulatory T cells and intestinal homeostasis. Immunol Rev 2005;204:184-94.

15. Macdonald TT, Monteleone G. Immunity, inflammation, and allergy in the gut. Science 2005;307:1920-5.

16. Casella G, Villanacci V, Fisogni S, Cambareri AR, Di Bella C, Corazzi $\mathrm{N}$, et al. Colonic left-side increase of eosinophils: A clue to drugrelated colitis in adults. Aliment Pharmacol Ther 2009;29:535-41.

17. Villanacci V, Casella G, Bassotti G. The spectrum of drug-related colitides: Important entities, though frequently overlooked. Dig Liver Dis 2011;43:523-8.

18. Villanacci V, Manenti S, Antonelli E, Chiudinelli M, Giuliano V, Bassotti G. Non-IBD colitides: Clinically useful histopathological clues. Rev Esp Enferm Dig 2011;103:366-72. 